논 문 16-12S-5

\title{
$\mathrm{BCl}_{3} / \mathrm{Ne}$ 혼합가스를 이용한 III-V 반도체의 고밀도 유도결합 플라즈마 식각
}

\section{High Density Inductively Coupled Plasma Etching of III-V Semiconductors in $\mathrm{BCl}_{3} / \mathrm{Ne}$ Chemistry}

\author{
백인규, 임완태, 이제원", 조관식 \\ (In Kyoo Baek, Wan Tae Lim, Je Won Lee; and Guan Sik Cho)
}

\begin{abstract}
A $\mathrm{BCl}_{3} / \mathrm{Ne}$ plasma chemistry was used to etch Ga-based (GaAs, AlGaAs, GaSb) and In-based (InGaP, InP, InAs and InGaAsP) compound semiconductors in a planar Inductively Coupled Plasma (ICP) reactor. The addition of the $\mathrm{Ne}$ instead of $\mathrm{Ar}$ can minimize electrical and optical damage during dry etching of $\mathrm{III}-\mathrm{V}$ semiconductors due to its light mass compared to that of Ar. All of the materials exhibited a maximum etch rate at $\mathrm{BCl}_{3}$ to $\mathrm{Ne}$ ratios of $0.25-0.5$. Under all conditions, the Ga-based materials etched at significantly higher rates than the In-based materials, due to relatively high volatilities of their trichloride etch products (boiling point $\mathrm{GaCl}_{3}: 201{ }^{\circ} \mathrm{C}, \mathrm{AsCl}_{3}: 130{ }^{\circ} \mathrm{C}, \mathrm{PCl}_{3}: 76{ }^{\circ} \mathrm{C}$ ) compared to $\mathrm{InCl}_{3}$ (boiling point : $600{ }^{\circ} \mathrm{C}$ ). We obtained low root-mean-square(RMS) roughness of the etched surface of both AlGaAs and GaAs, which is quite comparable to the unetched control samples. Excellent etch anisotropy $\left(>85^{\circ}\right.$ ) of the GaAs and $\mathrm{AlGaAs}$ in our $\mathrm{PICP} \mathrm{BCl}_{3} / \mathrm{Ne}$ etching relies on some degree of sidewall passivation by redeposition of etch products and photoresist from the mask. However, the surfaces of In-based materials are somewhat degraded during the $\mathrm{BCl}_{3} / \mathrm{Ne}$ etching due to the low volatility of $\mathrm{InCl}_{x}$.
\end{abstract}

Key Words : ICP, Dry etching, Compound semiconductor

\section{1. 서 론}

III-V 화합물 반도체의 건식식각 공정은 레이저 에서부터 이종접합 트랜지스터까지 다양한 종류의 소자응용에 지속적인 관심울 불러 일으키고 있다 [1-25]. 높은 aspect ratio의 비아(via) 홀 식각과 선택적 mesa 식각 같은 공정이 더욱 중요하게 여 겨짐에 따라 이온밀도와 이온과 중성자(neutral)의

* : 인제대학교 나노공학과/나노 기술 응용연구소 (경남 김해시 어방동 607 ,

Fax: 055-320-3631

Corresponding Author: jwlee@inje.ac.kr) 2003년 7월 30일 접수, 2003년 8월 27잃 1차 심사완토, 2003 년 10 월 14 일 최쫑 심사완료
비를 조절할 수 있는 고밀도 풀라즈마 (High Density Plasma, HDP) 시스템의 개발에 연구가 집중되어 왔다[1,15]. 현재 가장 많이 쓰이고 있는 $\mathrm{HDP}$ 시스템은 웨이퍼의 대구경화가 가능하고 폴 라즈마 발생이 쉬운 유도결합 플라즈마 (Inductively Coupled Plasma, ICP) 식각 장비이다 $[1,18]$. 지금까지 III-V 화합물 반도체룰 건식 식각 하는데 사용된 대부분의 ICP 장비는 실린더형 유 도결합 플라즈마 (Cylindrical ICP) 식각장비였다. 하지만 최근에는 이러한 CICP 보다 플라즈마 소스 형태플 쉅게 변화시킬 수 있고, RIE 척파워와 ICP 소스파워를 독립적으로 조절하여 이온밀도와 이온 에너지폴 조절할 수 있는 진보된 플라즈마 소스와 
시스템에 더욱 큰 관심을 가지고 있다. 특히 본 연 구에 사용된 평판형(planar) 유도결합 플라즈마 장 비는 RIE 척파워의 보조 없이 낮은 ICP 소스파워 ( < $300 \mathrm{~W}$ )에서도 플라즈마가 쉽게 점화하였다. 따라서 평판형 유도결합 플라즈마는 낮은 이온에 너지 사용을 선호하는 화합물 반도체 소자 식각이 나 표면클리닝과 박막제거 같은 공정에도 아주 유 용하게 이용할 수 있을 것이다. 이러한 장점 때문 에 최근에는 평판형 유도결합 플라즈마 장비를 이 용한 화합물 반도체 소자 식각을 더욱 선호하고 있다. 일반적으로 이온보조효과롤 얻기 위해 불할 성 가스인 $\mathrm{Ar}$ 을 혼합하지만 $\mathrm{Ar}$ 은 원자 질량이 커 서(40 AMU) $\mathrm{Ar}$ 이온의 물리적 충돌에 의해 전기 적 손상에 민감한 $\mathrm{III-V}$ 화합물 반도체의 건식 식 각시 소자의 성능을 저하시칼 우려가 있다. 따라서 본 논문에서는 평면 형태의 ICP 소스인 평판형 유 도결합 플라즈마 장비에 불활성 성질을 가지고 있 으며 $\mathrm{Ar}$ 에 비해 상대적으로 가벼워 혼합가스의 물 리적 충돌에 의한 전기적 손상을 감소시킬 수 있 는 $\mathrm{Ne}(20 \mathrm{AMU})$ 을 사용하여 $\mathrm{Ga}$ 기반 (GaAs, $\mathrm{AlGaAs}, \mathrm{GaSb}$ )과 In기반 (InP, InGaP, InAs, $\mathrm{InGaAsP}$ ) 반도체 소자들을 건식 식각 후 그 특성 을 분석하였다.

\section{2. 실 험}

본 실험에 사용된 $\mathrm{GaAs}, \mathrm{InP}, \mathrm{InAs}$ 웨이퍼는 Czochralski 방법을 이용하여 (100) 방향으로 성장 하였고 도핑은 하지 않았다. $\quad \mathrm{In}_{0.5} \mathrm{Ga}$ a.5P 과 $\mathrm{Al}_{0.2} \mathrm{Ga}_{0.8} \mathrm{As}$ 는 각각 금속유기 분자선 에피택시 (Metal Organic Molecule Beam Epitaxy, MOMBE)와 금속유기 화학기상증착 (Metal Organic Chemical Vapor Deposition)법을 이용하 여 $\mathrm{GaAs}$ 기판위에 격자정합 시켜 $1 \mu \mathrm{m}$ 두께로 성 장하였다. InGaAsP $(\lambda=1.55 \mu \mathrm{m})$ 는 $\mathrm{MOMBE}$ 방법으로 $\mathrm{InP}$ 기판위에 $1 \mu \mathrm{m}$ 두께로 성장하였다. 이때 에피층 역시 도핑하지 않았다.

식각은 (주) 클라이오텍과 본 연구진이 공동으로 개발하여 만든 평판형 $\mathrm{ICP}$ 장비 (모델명 $\mathrm{APE} 510$ ) 로 하였다[26]. RIE 척(최대파워 $600 \mathrm{~W}$ )과 $\mathrm{ICP}$ 소 스(최대파워 $1,200 \mathrm{~W}$ )에는 각각 $13.56 \mathrm{MHz}$ 의 $\mathrm{RF}$ 전원이 연결되어 있고, 공정온도는 열 교환기를 이 용하여 실온 $\left(25{ }^{\circ} \mathrm{C}\right)$ 을 유지하였다. 공정 중에는 $\mathrm{BCl}_{3}$ 가스의 응축을 막기 위해 가스 라인은 열선
을 이용하여 항상 $40{ }^{\circ} \mathrm{C}$ 이상을 유지하였다. 연구 에 사용된 ICP 장비의 웨이퍼 척 사이즈는 4 인치 용이었다. $1 \mu \mathrm{m}$ 두께의 감광액 (photoresist)으로 패턴된 $1 \times 1 \mathrm{~cm}^{2}$ 크기의 샘플들을 어노다이징 (anodizing)된 알루미늄 캐리어 위에 진공 그리스 로 고정한 상태로 실험하였다. 이때 알루미늄 캐리 어는 클램프를 사용하여 고정하고, 총 $20 \mathrm{sccm}$ (standard cubic centimeters per minute)의 $\mathrm{BCl}_{3} / \mathrm{Ne}$ 혼합가스를 $\mathrm{MFC}$ (mass flow controller) 를 통해 반응기내로 유입하였다. ICP 소스파워 10 - $500 \mathrm{~W}), \mathrm{RIE}$ 척퐈워 $(0-150 \mathrm{~W})$ 를 변화시키며 실험하였고, 공정 중 폴라즈마 상태를 in-situ 로 관찰하기 위해 광학발광 분광기 (Optical Emission Spectroscopy, OES)를 사용하였다. 식각 공정 후 전자주사현미경 (scanning electron microscopy, $\mathrm{SEM}$ )과 원자힘 현미경 (atomic force microscopy, $\mathrm{AFM})$ 으로 표면 분석을 하였다.

\section{3. 결과 및 토론}

그림 1 은 ICP 소스파워 $(300 \mathrm{~W}), \mathrm{RIE}$ 척파워 $(100 \mathrm{~W})$, 공정압력 (7.5 mTorr)을 고정시킨 상태 에서 $\mathrm{BCl}_{3}$ 비율에 따른 $\mathrm{GaAs}, \mathrm{AlGaAs}, \mathrm{InGaP}$, $\mathrm{GaSb}$ (위) 와 $\mathrm{InP}, \mathrm{InSb}, \mathrm{InGaAsP}$ (아래)의 식각률 을 보여주고 있다. $\mathrm{BCl}_{3}$ 에 $\mathrm{Ne}$ 을 혼합하면 처음에 는 식각률이 증가하는 것을 볼 수 있다. 본 실험 중에 광학분광기를 이용하여 $\mathrm{Cl}$ peak의 강도를 실 시간으로 분석한 결과 $\mathrm{BCl}_{3}$ 에 $\mathrm{Ne}$ 을 혼합하였을 때 순수한 $\mathrm{BCl}_{3}$ 플라즈마에서보다 전반적으로 $\mathrm{Cl}$ peak의 세기가 증가하는 것을 알 수 있었다. 하지 만 $\mathrm{BCl}_{3}$ 의 비율이 $25-50 \%$ 이하가 되면 반응기 내의 $\mathrm{Cl}$ 의 밀도가 감소하여 화학적인 식각성분이 줄어들게 되어 식각률이 급격히 떨어지는 것을 확 인할 수 있었다. 또, In을 포함하지 않은 반도체는 In을 포함하는 반도체 보다 식각률이 거의 10 배 이상 높았다. 이 결과는 상온에서 $\mathrm{BCl}_{2} / \mathrm{Ne}$ 유도결 합 플라즈마를 사용하여 $\mathrm{In}$ 기반반도체 소자 식각 시 $\mathrm{InCl}_{3}$ 라는 휘발성이 낮은(꼻는점: $600{ }^{\circ} \mathrm{C}$ ) 식각 부산물이 형성되기 때문이다. 따라서 $\mathrm{Cl}_{2}$-기반 플 라즈마를 이용하여 In을 포함하는 반도체 소자 식 각시 식각률을 증가시키고 표면에 과도한 양의 $\mathrm{Cl}$ 패시베이션 (passivation)을 막기 위해서는 웨이퍼 온도를 $130{ }^{\circ} \mathrm{C}$ 까지 올려주어야 한다. 

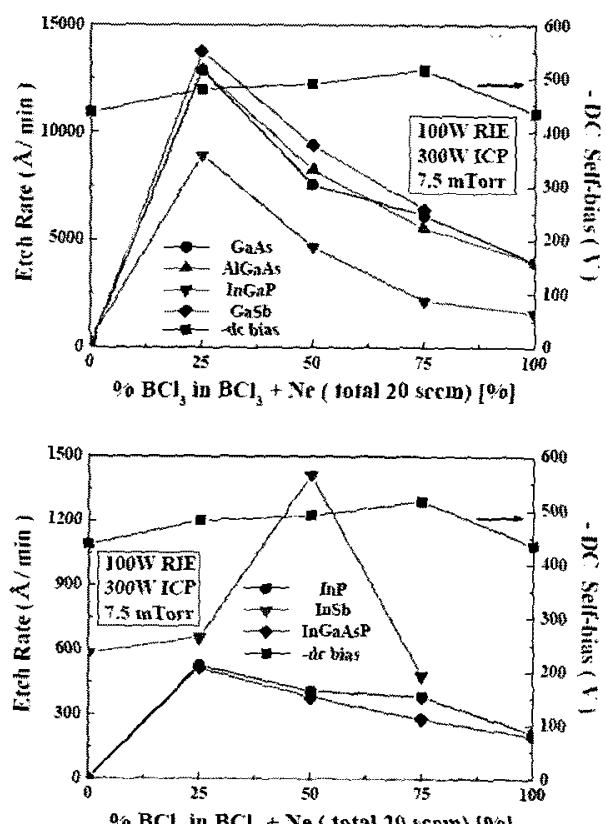

그림 1. $\mathrm{BCl}_{3} / \mathrm{Ne}$ 폴라즈마에서 $\% \mathrm{BCl}_{3}$ 에 따른 $\mathrm{GaAs}, \mathrm{AlGaAs}, \mathrm{InGaP}, \mathrm{GaSb}$ (위)와 $\mathrm{InP}$, $\mathrm{InSb}, \operatorname{InGaAsP}$ (아래)의 식각률.

Fig. 1. Etch rates of GaAs, AlGaAs, InGaP, GaAs (top) or InP, InSb, InGaAsP (bottom) as a function of $\mathrm{BCl}_{3}$ per centage in $\mathrm{BCl}_{3} / \mathrm{Ne}$ PICP discharges.

$15 \mathrm{BCl}_{3} / 5 \mathrm{Ne}, 100 \mathrm{~W}$ RIE 척파워, $300 \mathrm{~W} \mathrm{ICP}$ 소스퐈워, 7.5 mTorr의 공정압력에서 GaAs 을 식 각한 후 관찰한 $\mathrm{SEM}$ 사진과 $\mathrm{AFM}$ 데이터를 그림 2 예 나타내었다.

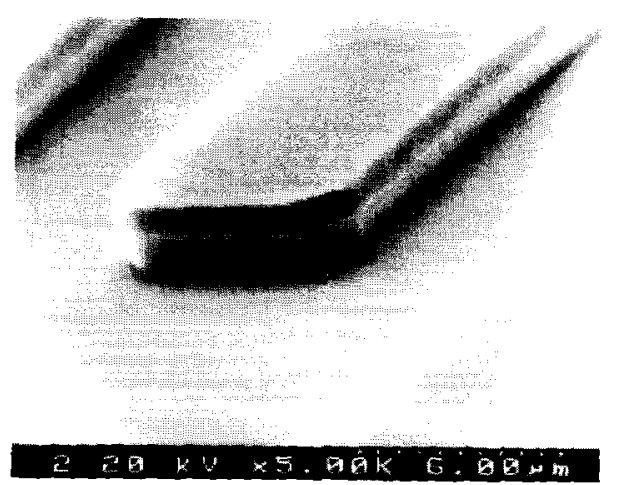

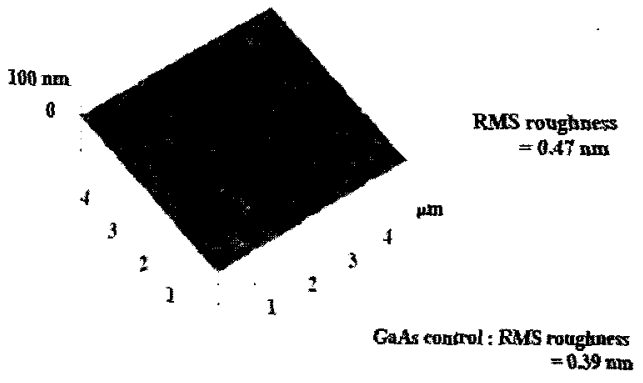

그림 2. $15 \mathrm{BCl}_{3} / 5 \mathrm{Ne}$ 풀라즈마로 식각 후 $\mathrm{GaAs}$ 의 $S E M$ 사진과 $A F M$ 테이터.

Fig. 2. An SEM micrograph of feature etched into GaAs (top) and an AFM of etched surface (bottom) at a $15 \mathrm{BCl}_{3 / 5} \mathrm{Ne}$ plasma.
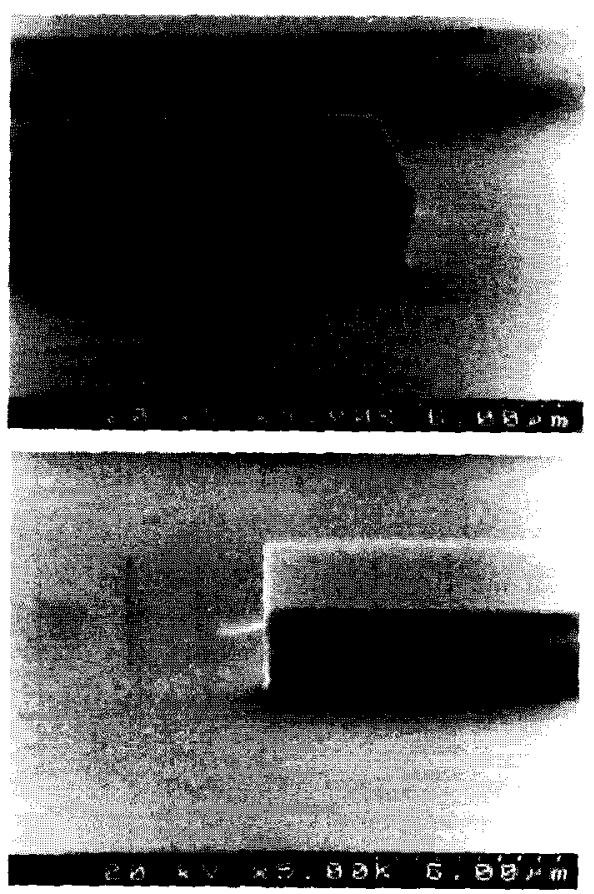

그림 3. $10 \mathrm{BCl} 3 / 10 \mathrm{Ne}$ 플라즈마를 사용하여 식각한 $\mathrm{GaAs}$ (위) 와 $\mathrm{AlGaAs}$ (아래) 의 SEM 사 진.

Fig. 3. SEM micrographs of features etched into GaAs(top) and AlGaAs(bottom) using a $10 \mathrm{BCl} / 10 \mathrm{Ne}$ plasma. 

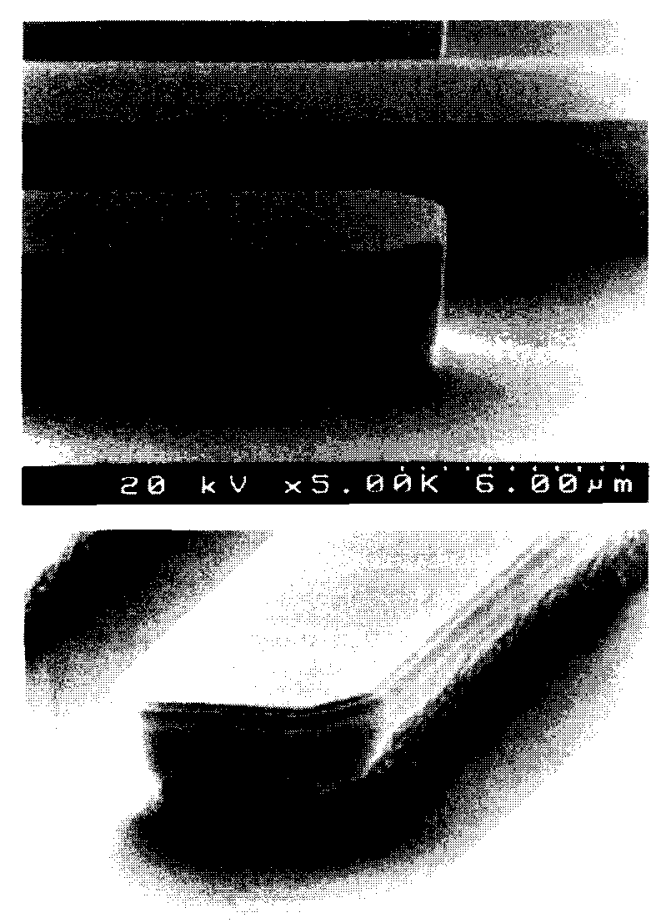

\section{$20 \mathrm{kV} \times 5.06 \mathrm{k} .6 .00 \% \mathrm{~m}$}

그림 4. $5 \mathrm{BCl} / / 15 \mathrm{Ne}$ 플라즈마롤 이용하여 식각한 $\mathrm{GaAs}$ (위) 와 $\mathrm{AlGaAs}$ (아래) 의 $\mathrm{SEM}$ 사진.

Fig. 4. SEM micrographs of features etched into GaAs (top) and AlGaAs (bottom) using a $5 \mathrm{BCl} 3 / 15 \mathrm{Ne}$ plasma.

식각된 $\mathrm{GaAs}$ 샘플의 수직측벽도 $\left(87^{\circ}\right)$ 와 표면은 매우 우수한 결과를 나타내었다. 총 식각 깊이는 $1.8 \mu \mathrm{m}$ 이고, 식각된 $\mathrm{GaAs}$ 의 RMS 표면 거칠기 는 $0.47 \mathrm{~nm}$ 로 식각전 $(0.39 \mathrm{~nm})$ 과 비교하였을 때 거의 변화가 없었다. 그리고 $\mathrm{GaAs}$ 와 감광액 (photoresist)의 선택도는 $~ 3.1: 1$ 이었다.

$100 \mathrm{~W}$ RIE 척파워, $300 \mathrm{~W} \mathrm{ICP}$ 소스파워, 7.5 mTorr 의 공정압력에서 $10 \mathrm{BCl}_{3} / 10 \mathrm{Ne}$ (그림 3) 5 $\mathrm{BCl}_{3} / 15 \mathrm{Ne}$ (그림 4) 플라즈마를 이용하여 $\mathrm{GaAs}$ (위)와 $\mathrm{AlGaAs}$ (아래)를 식각한 후 찍은 $\mathrm{SEM}$ 사 진을 그림 3과 4 에 나타내었다. $2.3-3.9 \mu \mathrm{m}$ 의 식각 깊이에도 불구하고 $\mathrm{GaAs}$ 와 $\mathrm{AlGaAs}$ 의 RMS 표면 거칠기는 $1.2 \mathrm{~nm}$ 이하로 매우 평탄한 표면을 얻을 수 있었다. 그리고 $\mathrm{GaAs}$ 대 $\mathrm{PR}$ 의 선택도는
$3.5-4.3: 1$ 로 높은 결과를 얻었다. 식각단면 또 한 우수하였지만 패턴이 형성된 표면 아랫부분에 는 약간의 undercut이 일어났다. 이 결과로부터, 우리는 $\mathrm{BCl}_{3}$ 의 함유량이 적으면 $\mathrm{PR}$ 이나 $\mathrm{BCl}_{x}$ 와 같 은 식각 부산물이 벽면을 패시베이션 시킬 만큼 충분히 증착 되지 않아 undercut의 원인이 될 수 있다는 것을 알았다. 반면에 $\mathrm{BCl}_{3}$ 의 함유량이 많은 조건에서는 높은 식각률 뿐만 아니라 우수한 수직 측벽도를 얻을 수 있었다.
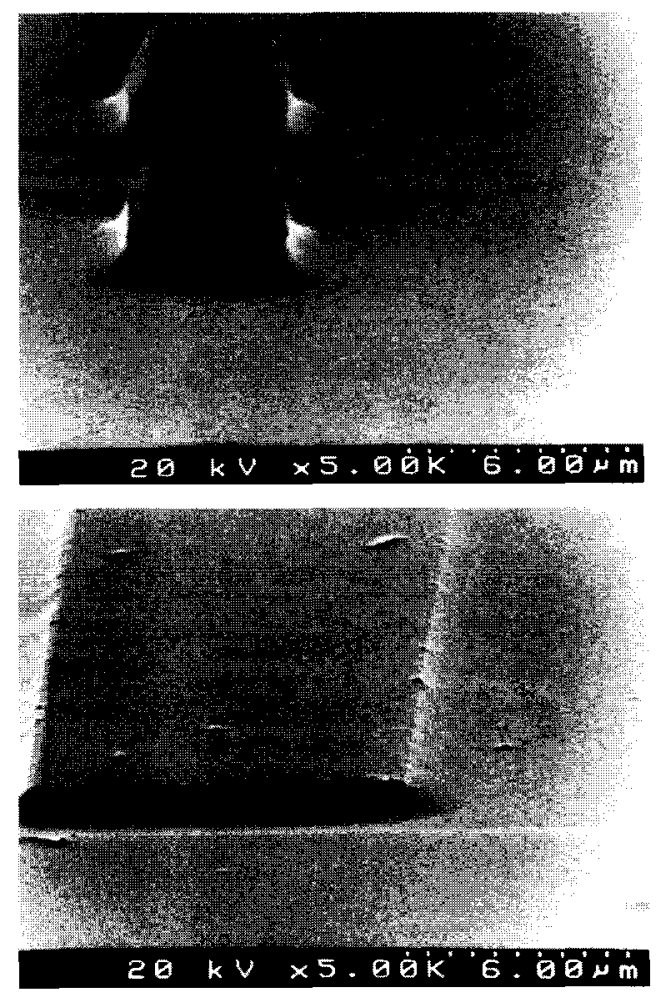

그림 5. $10 \mathrm{BCl}_{3} / 10 \mathrm{Ne}$ 플라즈마를 사용하여 식각 한 $\mathrm{InGaP}($ 위 $)$ 과 $\mathrm{InP}$ (아래)의 $\mathrm{SEM}$ 사진.

Fig. 5. SEM micrographs of features etched into $\mathrm{InGaP}$ (top) and $\mathrm{InP}$ (bottom) using a $10 \mathrm{BCl}_{3} / 10 \mathrm{Ne}$ plasma.

$\mathrm{GaAs}, \mathrm{AlGaAs}$ 와는 대조적으로, 같은 공정 조건 에서 In을 포함하는 반도체 소자들의 경우는 거친 표면과 경사진 측벽을 얻었다. 이 결과를 그림 5와 6 에 나타내었다. 그림 5 에서는 $10 \mathrm{BCl}_{3} / 10 \mathrm{Ne}$, 그 림 6 에서는 $5 \mathrm{BCl}_{3} / 15 \mathrm{Ne}$ 폴라즈마에서의 $\mathrm{InGaP}$ (위) 과 $\mathrm{InP}$ (아래)의 $\mathrm{SEM}$ 사진을 보여주고 있다. 


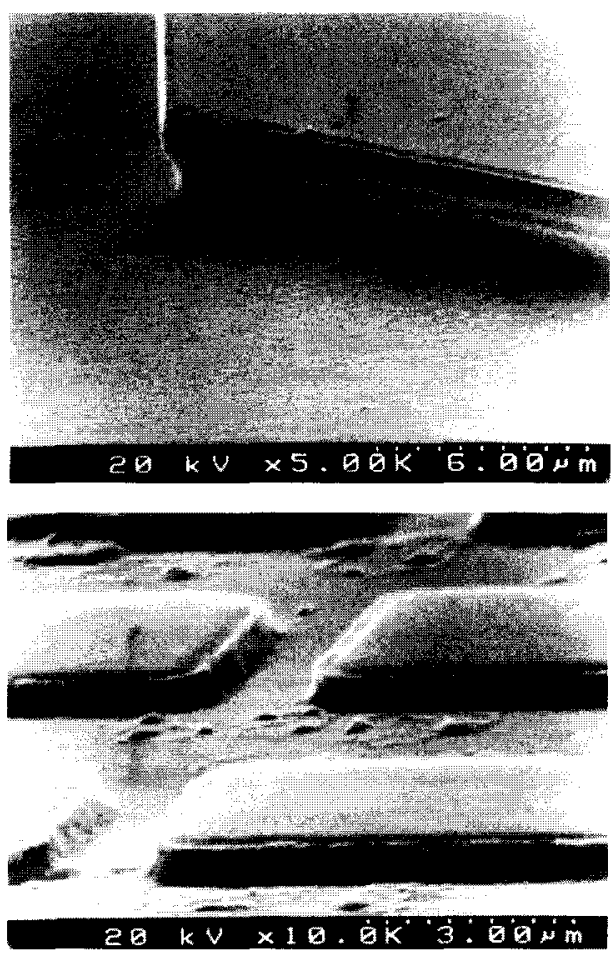

그림 6. $5 \mathrm{BCl}_{3} / 15 \mathrm{Ne}$ 풀라즈마룰 이용하여 식각한 $\mathrm{InGaP}($ 위 $)$ 과 $\mathrm{InP}$ (아래)의 $\mathrm{SEM}$ 사진.

Fig. 6. SEM micrographs of features etched into InGaP (top) and InP (bottom) using a $5 \mathrm{BCl}_{3} / 15 \mathrm{Ne}$ plasma.

In기반 반도체의 경우는 휘밝성이 서로 다론 식 각 부산뚤들 $\left(\mathrm{InCl}_{3}, \mathrm{GaCl}_{3}, \mathrm{PCl}_{3}\right)$ 로 인한 선택적 손 실 (preferential loss)을 가져와 그림에서처럼 경사 진 식각단면을 나타내었다. 그리고 $\mathrm{InGaP}$ 의 샘폴 의 undercut은 그림 3과 4에서 알 수 있듯이 $1 \mu$ $\mathrm{m}$ 두께의 $\mathrm{InGaP}$ 층 아래에 있는 패시베이션 되지 않은 $\mathrm{GaAs}$ 기판의 식각에 의해 나타난 결과이다.

그림 7에서는 ICP 소스카워에 따른 III-V 화합 물 반도체 소자의 식각률을 보여주고 있다. ICP 소 스파워가 $0-500 \mathrm{~W}$ 로 변하면 $\mathrm{Cl}(774.27,798.8$, $820.32,955.45 \mathrm{~nm})$ 과 $\mathrm{Ne}$ 의 이온과 라디칼 그리고 $\mathrm{BCl}_{3}$ 분자의 $(350-650 \mathrm{~nm})$ 밀도가 증가하여 $\mathrm{Ga}$ 기반 반도체 소자의 식각률을 증가시켰다. $\mathrm{InCl}_{3}$ 의 결합에너지 $(39.4 \mathrm{kcal} / \mathrm{mol})$ 는 $\mathrm{GaCl}_{3}(11.4 \mathrm{kcal} / \mathrm{mol})$ 보다 높아서 실온에서는 휘발되기가 어렵다. 따라 서 $\mathrm{Cl}_{2}$ 기반 가스들을 이용하여 In을 포함하는 반도 체의 식각률을 높이기 위한 방법으로는 샘폴 온도
( > $130{ }^{\circ} \mathrm{C}$ )를 올리거나 $\mathrm{InCl}_{\mathrm{x}}$ (녹는점 : $600{ }^{\circ} \mathrm{C}$ ) 보다 휘발성이 높은 $\mathrm{I}_{2}\left(\mathrm{InI}_{x}: 210{ }^{\circ} \mathrm{C}\right)$ 기반 가스를 사용하여 식각하는 것이 좋다.
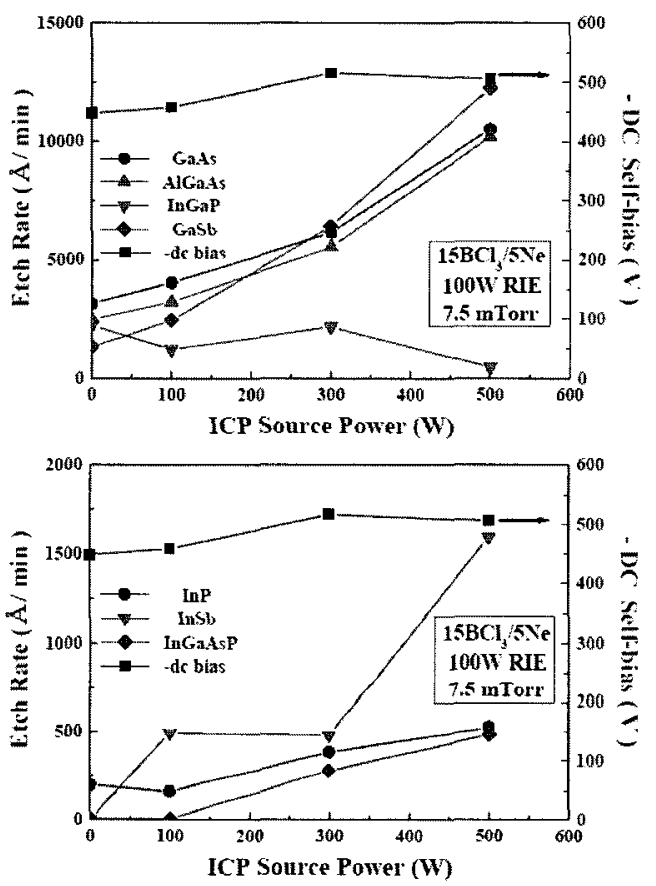

그림 7. ICP 소스퐈워에 따른 III-V 화합물 반도 체 소자의 식각룰.

Fig. 7. Etch rates of III-V compound semicond uctors as a function of ICP source power at $15 \mathrm{BCl}_{3} / 5 \mathrm{Ne}, 100 \mathrm{~W}$ RIE chuck power and 7.5 mTorr.

$15 \mathrm{BCl}_{3} / 5 \mathrm{Ne}$ 폴라즈마를 이용하여 $7.5 \mathrm{mTorr}$ 의 공정압력을 유지한 상태로 ICP 소스파워와 RIE 척퐈워에 따른 $\mathrm{OES}$ 데이터를 그림 8에 나타내었 다. $100 \mathrm{~W}$ ICP 소스파워에서는 반응기내의 발팡 하는 빛의 세기가 $0 \mathrm{~W} \mathrm{ICP} \mathrm{소스파워와의} \mathrm{그것과}$ 비교하였을 때 거의 변하지 않았다. 이 조건에서는 capacitively coupled plasma (CCP) 형태가 여전히 지배적이라는 것을 말해준다. 하지만 $300 \mathrm{~W} \mathrm{ICP}$ 소스파워에서는 반응기에 있는 플라즈마 내에서 $\mathrm{BCl}_{3}$ 분자 peak이 급격히 증가하고 $\mathrm{Cl}$ 원자 peak 의 세기도 커져 inductively coupled plasma (ICP) 의 톡징을 나타내고 있다.

그리고, $\mathrm{BCl}_{3}$ 와 $\mathrm{Ne}$ 의 혼합가스를 사용한 유도결 합 플라즈마의 경우, $\mathrm{RIE}$ 척퐈워의 증가는 반응기 

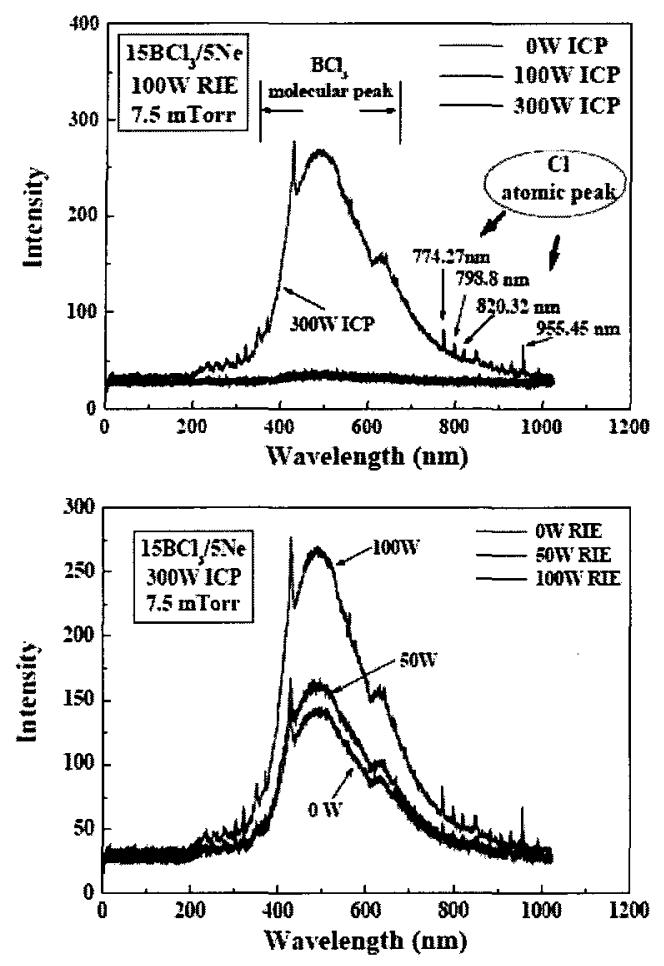

그림 8. $15 \mathrm{BCl}_{3} / 5 \mathrm{Ne}$ 폴라즈마의 $\mathrm{ICP}$ 소스파워 와 $\mathrm{RIE}$ 척파워에 따른 $\mathrm{OES}$ 데이터.

Fig. 8. OES spectra from $15 \mathrm{BCl} / 5 / 5 \mathrm{Ne}$ dischar ges as a function of ICP source power (top) and RIE chuck power (bottom).

내의 발광하는 빛의 세기를 증가시킨다는 훙미로 운 결과를 얻을 수 있었다. 같은 공정조건에서 20 $\mathrm{BCl}_{3}$ 나 $15 \mathrm{BCl}_{3} / 5 \mathrm{Ar}$ 플라즈마를 사용하여 관찰한 $\mathrm{OES}$ 결과에는 $\mathrm{RIE}$ 척파워가 증가해도 $\mathrm{OES}$ peak 세기는 거의 변화가 없었다. 이 결과로부터 $\mathrm{BCl}_{3}$ 나 $\mathrm{BCl}_{3} / \mathrm{Ar}$ 플라즈마에서는 $\mathrm{RIE}$ 척파워가 모두 sheath 내의 이온을 가속시키는데 소모되지만 $\mathrm{BCl}_{3} / \mathrm{Ne}$ 플라즈마에서는 $\mathrm{RIE}$ 척파워가 모두 이온 을 가속시키는데 소모된 것이 아니고 일부 에너지 가 플라즈마 내에 전달되어 플라즈마의 밀도증가 에도 영향을 미치는 것으로 사료된다. 또한 $\mathrm{BCl}_{3} / \mathrm{Ne}$ 평판형 유도결합 플라즈마에서 $\mathrm{Ne}$ 원자들 의 충돌은 $\mathrm{BCl}_{3}$ 분자들을 여기 시키는데 아주 효 과적이라는 것을 예상할 수 있다.

$15 \mathrm{BCl}_{3} / 5 \mathrm{Ne}, 300 \mathrm{~W}$ ICP 소스파워, 7.5 m'Torr 의 공정조건에서 RIE 척파워에 따른 III-V 화합물 반도체 소자의 식각률을 그림 9 에 나타내었다.
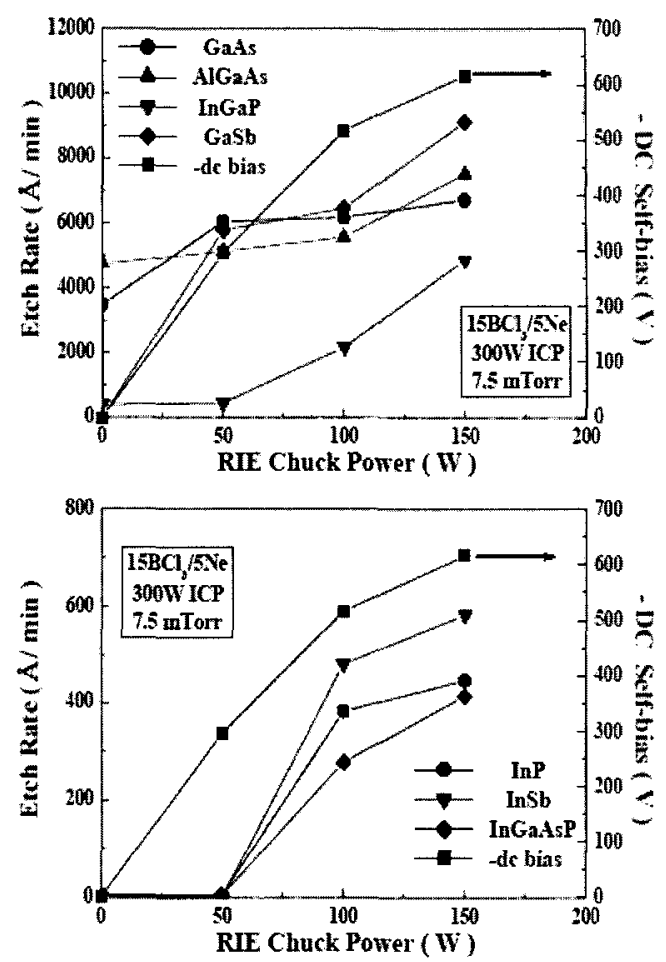

그림 9. $\mathrm{RIE}$ 척파워에 따른 III-V 화합물 반도 체 소자의 식각률.

Fig. 9. Etch rates of different III-V semicond uctors as a function of RIE chuck power at $15 \mathrm{BCl}_{3} / 5 \mathrm{Ne}, 300 \mathrm{~W}$ ICP source power and $7.5 \mathrm{~m}$ Torr.

$\mathrm{RIE}$ 척파워의 증가는 샘플에 충돌하는 이온에너 지를 증가시킬 뿐만 아니라 그림 8에서도 알 수 있듯이 $\mathrm{BCl}_{3} / \mathrm{Ne}$ 평판형 유도결합 폴라즈마에서는 그것이 플라즈마 말도를 증가시켜 식각률을 더욱 증가시킨 것으로 예측된다. 그리고 In을 포함하는 반도체 소자의 경우는 최소 $50 \mathrm{~W}$ 이상의 $\mathrm{RIE}$ 척 파워가 인가되어야 이온에너지 증가와 같은 이온 보조 효과에 의해 소자가 식각되기 시작한다는 것 을 알 수 있었다. 특히 이번 연구에 사용된 $\mathrm{PICP}$ 시스템은 $\mathrm{RIE}$ 척파워의 보조없이 $10 \mathrm{~W} \mathrm{RIE}$ 척파 워) 낮은 ICP 소스파워 $(<300 \mathrm{~W}$ )에서도 플라즈 마가 쉽게 점화하였다. 따라서 평판형 유도결합 플 라즈마는 낮은 이온에너지 사용을 선호하는 화합 물 반도체 소자 식각이나 표면클리닝과 박막졔거 같은 공정에도 아주 유용하게 이용할 수 있을 것 이다. 


\section{4. 요약 및 결론}

본 연구에서는 평판형 유도결합 $\mathrm{BCl}_{3} / \mathrm{Ne}$ 플라즈 마 (PICP)를 이용하여 III-V 화합물 반도체의 건 식식각 결과를 분석하였다. $\mathrm{OES}$ 를 이용한 평판형 유도결합 $\mathrm{BCl}_{3} / \mathrm{Ne}$ 플라즈마 peak들의 분석결과 낮 은 ICP 소스파워 $(<100 \mathrm{~W}$ )에서는 ICP 소스파워 가 증가해도 $(0-100 \mathrm{~W})$ 플라즈마 밀도에 영향을 거의 주지 않았다는 것을 알 수 있었다. 그리고, $\mathrm{PICP}$ 시스템은 $\mathrm{RIE}$ 척파워의 보조없이 (즉, $0 \mathrm{~W}$ $\mathrm{RIE}$ 척파워) 낮은 $\mathrm{ICP}$ 소스파워(300W ICP 소스파 워)만으로도 플라즈마를 발생할 수 있다는 장점을 가지고 있어서 공정에 의한 손상에 민감한 화합물 반도체 식각에 유용하게 쓰일 수 있다. 평판형 유 도결합 $\mathrm{BCl}_{3} / \mathrm{Ne}$ 을 이용한 III-V 화합물 반도체의 건식식각에서 $\mathrm{Ga}$ 기반과 $\mathrm{In}$ 기반의 화합물 반도체의 식각률은 $\mathrm{BCl}_{3}$ 의 혼합비가 $25-50 \%$ 의 범위일 때 가장 높았다. 그러나 $25 \%$ 이하의 $\mathrm{BCl}_{3}$ 가 혼합 된 플라즈마에서는 반응기내의 $\mathrm{BCl}_{3} / \mathrm{Ne}$ 중 $\mathrm{BCl}_{3}$ 가스의 함유량 감소로 인한 화학적 식각 성분이 줄어들어 식각률이 감소하였다. $\mathrm{BCl}_{3} / \mathrm{Ne}$ 평판형 유 도결합 플라즈마를 이용한 건식식각 후, 특히 $\mathrm{Ga}$ 기반 반도체의 경우는 높은 식각률 $(3,000$ $11,000 \AA / \mathrm{min})$, 깨끗한 표면, 우수한 수직측벽도( $>85^{\circ}$ ), 그리고 평탄한 표면(RMS roughness < $1 \mathrm{~nm})$ 을 얻을 수 있었다. 그러나, In을 포함하는 반도체 소자의 경우에는 식각 후 경사진 측벽과 다소 거친 표면을 얻었으며 그것은 상온에서 낮은 휘발성을 가지는 식각부산물인 $\mathrm{InCl}_{\mathrm{x}}$ 때문이라고 사료된다. 따라서, $\mathrm{BCl}_{3} / \mathrm{Ne}$ 가스를 이웅한 평판형 유도결합 폴라즈마 시스템은 $\mathrm{Ga}$ 기반 III-V 화합물 반도체 소자의 풀라즈마 식각 공정시 진보된 플라 즈마 소스로 더욱 유용하게 이용될 수 있을 것이 다.

\section{감사의 글}

본 연구는 한국과학재단 지역대학 우수과학자 연구비지원(과제번호 : R05-2002-000013680-2003) 에 의해 수행되었습니다. 본 연구에 기술적인 지원 을 준 (存) 클라이오텍의 조국산, 정다정, 부경대학 교 공동실혐 실습관의 류호정 박사께 감사드립니 다.

\section{잠고 문헌}

[1] C. Youtsey and I. Adesida, "Chapter 11 in Handbook of Advanced Plasma Processing Techniques", eds., R. J. Shul (Springer, Berlin, 2000.

[2] S. J. Pearton, J. W. Lee, E. S. Lambers, C. R. Abernathy, F. Ren, W. S. Hobson, and R. J. Shul, "Comparison of dry etching technologies for III- $\mathrm{V}$ semiconductors in $\mathrm{CH}_{4} / \mathrm{H}_{2} / \mathrm{Ar}$ plasmas", J. Electrochem. Soc. 143, p. 752, 1996.

[3] 이수부, 박헌건, 이석현, "유도결합형 플라즈 마원을 이용한 고선택비 산화막 식각에 관한 연구", 전기전자재료학회논문지, 11 권, 4 호, p. 261, 1998.

[4] J. W. Lee and S. J. Pearton, "Investigation of masking materials for high ion density $\mathrm{Cl}_{2} / \mathrm{Ar}$ plasma etching of GaAs", Semicond. Sci. Technol. 11, p. 812, 1996.

[5] K. Mochizuki, T. Oka, K. Ouchi, and T. Tanoue, "Reliability investigation of heavily C-doped InGaP/GaAs HBTs operated under a very high current-density condition", Solid-State Electron. 43, p. 1425, 1999.

[6] J. W. Lee, J. Hong, C. R. Abernathy, E. S. Lambers, S. J. Pearton, W. S. Hobson, and F. Ren, " $\mathrm{Cl}_{2} / \mathrm{Ar}$ plasma etching of binary, ternary and quaternary In-based compound semiconductors", J. Electrochem. Soc. J. Vac. Sci. Technol. B 14, p. 2567, 1996.

[7] J. W. Lee, C. R. Abernathy, S. J. Pearton, F. Ren, W. S. Hobson, R. J. Shul, C. Constantine, and C. Barratt, "Inductively coupled plasma etch damage in GaAs and InP schottky diodes", J. Electrochemical Society 144, p. 1417, 1997.

[8] 김창일, 권광호, "ICP에 의한 $\mathrm{BCl}_{3} / \mathrm{Cl}_{2}$ 폴라즈 마 내에서 $\mathrm{Pt}$ 박막의 식각 톡성", 전기전자재 료학회논문지, 11권, 10호, p. 804, 1998.

[9] 김성대, 정석용, 이병택, 허증수, " $\mathrm{BCl}_{3} / \mathrm{H}_{2} / \mathrm{Ar}$ 유도결합 플라즈마를 이용한 $\mathrm{GaN}$ 의 건식 식 각에 관한 연구", 한국재료학회지, 10 권, 3 호, p. $179,2000$.

[10] R. J. Shul, G. B. McClellan, R. D. Rriggs, D. J. Rieger, S. J. Pearton, C. R. 
Abernathy, J. W. Lee, C. Constantine, and C. Barratt, "High density plasma etching of compound semiconductors", J. Vac. Sci. Technol. A 15, p. 633, 1997.

[11] J. W. Lee, C. R. Abernathy, S. J. Peaton, F. Ren, C. Constantine, C. Barratt, and R. J. Shul, "Dry etch damage in inductively coupled plasma exposed GaAs/AlGaAs heterojunction bipolar transistor", Appl. Phys. Lett., 70, p. 2410, 1997.

[12] 류재홍, 김남훈, 장의구, 김창일, ${ }^{\prime} \mathrm{Cl}_{2} / \mathrm{Ar}$ 유도 결합 플라즈마에서 $\mathrm{Pt}$ 박막 식각시 $\mathrm{N}_{2}$ 가스 첨가 효과", 대한전자공학회 논문지, 37 권, 7 호, p. $513,2000$.

[13] 박준용, 김현수, 권광호, 김곤호, 염근영, "유도 결합형 $\mathrm{Ar} / \mathrm{CH}_{4}$ 플라즈마를 이용한 ITO의 식 각 특성에 관한 연구", 한국진공학회지, 8권, 4(2)호, p. 565, 1999.

[14] 유석빈, 김남훈, 김창일, 장의구, "도핑되지 않 은 비정질 실리콘의 고밀도 $\mathrm{Cl}_{2} / \mathrm{HBr}$ 플라즈 마에 의한 식각 시 나칭 효과", 전기전자재료 학회논문지, 13권, 8호, p.651, 2000.

[15] J. W. Lee, M. W. Devre, B. H. Reelfs, D. Johnson, J. N. Sasserath, F. Clayton, D. C. Hays, and S. J. Pearton, "Advanced selective dry etching of $\mathrm{GaAs} / \mathrm{AlGaAs}$ in high density inductively coupled plasmas", J. Vac. Sci. Technol. A 18, p. 1220, 2000.

[16] 김현수, 이용혁, 이재원, 김태일, 염근영, ${ }^{\prime \prime} \mathrm{Cl}_{2} / \mathrm{H}_{2}$ 플라즈마 조건이 $\mathrm{n}-\mathrm{GaN}$ 의 식각톡성 및 저저항 접촉 형성에 미치는 영향", 한국재 료학회지, 9권, 5호, p. 496, 1999.

[17] R. J. Shul, G. B. McClellan, R. D. Rriggs, D. J. Rieger, S. J. Pearton, C. R. Abernathy, J. W. Lee, C. Constantine, and C. Barratt, "High density plasma etching of compound semiconductors", J. Vac. Sci. Technol. A 15, p. 633, 1997.

[18] 김현수, 이재원, 김태일, 염근영, "유도결합형 $\mathrm{Cl}_{2}$ 계 풀라즈마를 이용한 $\mathrm{GaN}$ 식각 특성에 관한 연구”, 한국표면공학회지, 32권, 3호, p. 83, 1999.

[19] 최익수, 이병택, 김동근, 박종삼, ${ }^{\prime} \mathrm{Cl}_{2} / \mathrm{CH}_{4} / \mathrm{H}_{2}$ 혼합기체를 이용한 $\operatorname{InP}$ 소재의 반응성 이온 에칭에 관한 연구", 한국진공학회지, 6 권, p. 282, 1997.
[20] J. W. Lee, J. Hong, E. S. Lambers, C. R. Abernathy, S. J. Pearton, W. S. Hobson and F. Ren, "Plasma etching of III-V semiconductor 'in $\mathrm{BCl}_{3}$ chemistries; Part I: GaAs and related materials", Plasma Chem. Plasma Phys. 17, p. 155, 1997.

[21] T. Chino, M. Ishino, $M$. Kito, and $Y$. Maksui, Proc, 1998 Int. Conf. InP and Related Materials, p. 709, 1998.

[22] 이병택, 박칠희, 김성대, 김호성, ${ }^{n} \mathrm{BCl}_{3} / \mathrm{O}_{2} / \mathrm{Ar}$ 유도결합 플라즈마를 이용한 $\mathrm{InP}$ 의 건식 식각 에 관한 연구", 한국진공학회지, 8권, p. 541, 1999.

[23] J. Hommel, D. Ottenwalder, V. Harle, F. Schneider, A. Menschig, F. Scholz and $H$. Schweizer, "Special angle technique with $\mathrm{Ar} / \mathrm{O}_{2}$ - RIBE for the fabrication of steep $\mathrm{NM}^{-}$scale profiles in InGaAsP/InP and subsequent epitaxial overgrowth", Microelectronic Eng. 21, p. 333, 1993.

[24] 염근영, "Cylindrical Magnetron을 이용한 실 리콘의 반응성 이온 건식식각의 특성에 관한 연구", 한국재료학회지, 3권, 4호, 1993.

[25] J. W. Lee, E. S. Lambers, C. R. Abernathy, S. J. Pearton, W. S. Hobson and F. Ren, "Plasma etching of III-V semiconductors in $\mathrm{BCl}_{3}$ chemistries; Part II: InP and related compounds", Plasma Chem. Plasma Phys. 17, p. 169, 1997.

[26] 임완태, 백인규, 정필구, 이제원, 조관식, 이주 인, 조국산, S. J. Pearton, "BCl3 평판형 유도 결합 플라즈마를 이용한 $\mathrm{GaAs}$ 건식식각", 한 국재료학회지, 13권, 4호, 266, 2003. 